\title{
Influence of Anticholinergic Activity in Serum on Clinical Symptoms of Alzheimer's Disease
}

\author{
Koji Hori $^{a, b}$ Kimiko Konishi ${ }^{a}$ Koichiro Watanabe ${ }^{b}$ Hiroyuki Uchida ${ }^{b}$ \\ Takashi Tsuboi $^{\text {b }}$ Matsuko Moriyasu ${ }^{d}$ Itaru Tominaga e Mitsugu Hachisu ${ }^{c}$ \\ ${ }^{a}$ Department of Psychiatry, Showa University Northern Yokohama Hospital, Yokohama, ${ }^{b}$ Department of \\ Neuropsychiatry, School of Medicine, Keio University, and 'Department of Clinical Psychopharmacy, School of \\ Pharmaceutical Sciences, Showa University, Tokyo, ${ }^{d}$ Mitsubishi Chemical Medience Corporation, Nonclinical

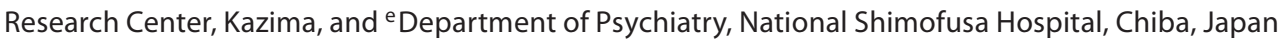

\section{Key Words}

Alzheimer's disease - Serum anticholinergic activity •

Clinical symptoms $\cdot$ Behavioral and psychological

symptoms of dementia

\begin{abstract}
Alzheimer's disease (AD) is well known as a disease characterized by degeneration of cholinergic neuronal activity in the brain. It follows that patients with AD would be sensitive to an 'anticholinergic burden', and also that medicine with anticholinergic properties would promote various clinical symptoms of $A D$. Despite the relevance of this important phenomenon to the clinical therapeutics of AD patients, few reports have been seen concerning the relationship between anticholinergic burden and clinical AD symptoms. Therefore, we wished to investigate the relationship between serum anticholinergic activity (SAA) and the severity of clinical symptoms of AD patients. Twenty-six out of $76 A D$ patients referred by practitioners to our hospital were positive for anticholinergic activity in their serum, and the remaining 50 patients were negative. Cognitive and psychiatric symptoms in $A D$ patients were compared between the positive SAA (SAA+) group and the negative SAA (SAA-)
\end{abstract}

\section{KARGER}

Fax +41613061234 E-Mail karger@karger.ch www.karger.com
(C) 2011 S. Karger AG, Basel

0302-282X/11/0633-0147\$38.00/0

Accessible online at:

www.karger.com/nps group. The SAA+ group showed a significantly $(p<0.05)$ lower total score on the Mini-Mental State Examination, and significantly $(p<0.05)$ higher scores on the Functional Assessment Staging and the Behavioral Pathology in Alzheimer's Disease Rating Scale (BEHAVE-AD). In particular, certain subscales of the BEHAVE-AD, i.e. the items of paranoid and delusional ideation, hallucinations and diurnal rhythm disturbances, had higher scores in the SAA+ group. Moreover, it was shown that many more psychotropic medicines were prescribed to the SAA+ group. By means of logistic regression analysis, the items of paranoid and delusional ideation and diurnal rhythm disturbances in the BEHAVE-AD were positively correlated with SAA in patients. We hypothesized that SAA in AD patients would be associated with clinical symptoms, especially delusion and diurnal rhythm disturbances.

Copyright $\odot 2011$ S. Karger AG, Basel

\section{Introduction}

Tune and Coyle [1] developed a radioreceptor assay technique to measure serum anticholinergic activity (SAA), and reported that there is an inverse correlation 
between the presence of extrapyramidal side effects due to neuroleptics and SAA in patients. Moreover, Tune et al. [2] consider that the appearance of SAA is a consequence of multiple psychotropic medicines. Mulsant et al. [3] detected SAA-positive (SAA+) subjects in certain community dwellings, and found that the activity comes from taking both prescribed and over-the-counter medicines. SAA is detected in some Alzheimer's disease (AD) patients even at first admission to hospital because they have already been prescribed cognitive enhancers together with antipsychotics to prevent behavioral and psychotic symptoms of dementia (BPSD) $[4,5]$. In contrast to the cognitively intact subjects, patients with central-cholinergic-deficiency-related dementia are exceptionally vulnerable to anticholinergic burdens $[6,7]$. AD is well known as a disease with degeneration of cholinergic neuronal activity in the brain. Therefore, especially when SAA is detected in AD patients at first admission to hospital, we should scrutinize medicines and reduce or exchange medicines with less anticholinergic burden in order to lessen this burden. Moreover, we should discuss the relationship between SAA and demographic data, global cognitive function and BPSD to consider the degree of cognitive and behavioral impairment in these patients. To our knowledge, however, there have been only a few reports describing the relationship between anticholinergic burden and clinical symptoms of dementia, i.e. BPSD, in $\mathrm{AD}$ patients. Therefore, in this study we have evaluated SAA and BPSD in AD patients referred by practitioners and admitted to our hospital in order to investigate the relationship of SAA to global cognitive function and BPSD.

\section{Patients and Methods}

Seventy-six patients with $\mathrm{AD}$ who regularly visited the $\mathrm{Na}$ tional Shimofusa Hospital (Chiba, Japan) from May 1, 2003, to March 31, 2005, were enrolled in this study. All subjects met the diagnostic criteria for probable $\mathrm{AD}$ assessed by a scale developed by a working group of the National Institute of Neurological and Communicative Disorders and Stroke in collaboration with the Alzheimer's Disease and Related Disorders Association [8]. Patients diagnosed with other psychiatric disorders (such as drug abuse) before the onset of dementia, as well as those with cerebral hemorrhage or infarction, were excluded from the study. We also excluded patients with active physical symptoms or with severe physical illnesses.

We evaluated demographic data (sex, educational level, age at dementia onset, age at the time of test, and severity of dementia), cognitive function, BPSD, the number of different kinds of prescribed psychotropic medicine taken (the number of prescribed psychotropic medicines) and prescribed nonpsychotropic medi-
Table 1. Demographic data in the SAA+ and SAA- groups

\begin{tabular}{lccc}
\hline & SAA+ & SAA- & $\mathrm{p}$ \\
\hline Number & $26(12 / 14)$ & $50(20 / 30)$ & 0.7867 \\
Educational level, years & $9.96(3.84)$ & $10.26(4.00)$ & 0.7553 \\
$\begin{array}{l}\text { Age at dementia onset } \\
\quad \text { years }\end{array}$ & $75.3(8.3)$ & $73.4(7.9)$ & 0.3323 \\
$\begin{array}{l}\text { Test age, years } \\
\text { MMSE score }\end{array}$ & $78.9(7.2)$ & $77.9(7.1)$ & 0.5460 \\
$\begin{array}{l}\text { FAST score } \\
\text { Number of psychotropic }\end{array} \quad 5.89(8.40)^{*}$ & $13.16(8.27)$ & 0.0367 \\
$\quad$ medications & $1.3(2.0)^{*}$ & $0.5(1.1)$ & 0.0234 \\
$\begin{array}{l}\text { Number of nonpsycho- } \\
\quad \text { tropic medications }\end{array}$ & $1.8(2.9)$ & $1.0(1.8)$ & 0.1456 \\
\hline
\end{tabular}

Data are given as means with SD in parentheses, except for the number of patients, where numbers in parentheses denote male/ female ratios. Number of prescribed psychotropic medicines: number of different kinds of prescribed psychotropic medicines taken. Number of prescribed nonpsychotropic medicines: number of different kinds of prescribed nonpsychotropic medicines taken. ${ }^{*} \mathrm{p}<0.05$.

cine taken (the number of prescribed nonpsychotropic medicines). The severity of dementia was evaluated by Functional Assessment Staging (FAST) [9]. Cognitive function was evaluated by the Mini-Mental State Examination (MMSE) [10], and BPSD were assessed by the Behavioral Pathology in Alzheimer's Disease Rating Scale (BEHAVE-AD) [11], which measures behavioral and psychological symptoms in 7 symptom domains such as paranoid and delusional ideation, hallucinations, activity disturbances, aggressiveness, diurnal rhythm disturbances, affective disturbance, and anxieties and phobias. The BEHAVE-AD is scored on a 4-point scale according to the severity of disease. We used the total score for each symptom domain of the BEHAVE-AD, except for diurnal rhythm disturbances, which is treated as a single item. All clinical data were collected at the first visit to our hospital (at study entry).

Blood samples were collected at study entry for evaluation of anticholinergic activity. The samples, which were clotted at room temperature, were centrifuged at 3,000 rpm for $15 \mathrm{~min}$, and the obtained serum samples were stored at $-80^{\circ} \mathrm{C}$ until the assay. To avoid diurnal changes in SAA, the blood samples were collected approximately at the same time, between 10.00 a.m. and 12.00 noon. Patient information was omitted from the samples. SAA was assayed according to the receptor-binding assay protocol by Tune and Coyle [1] at Mitsubishi Chemical Medience Corporation, Kazima, Japan. This assay is based upon the fact that the potent muscarinic receptor antagonist $\left[{ }^{3} \mathrm{H}\right]$ radiolabeled quinuclidinyl benzilate ( $\left.\left[{ }^{3} \mathrm{H}\right] \mathrm{QNB}\right)$ binds specifically and avidly to muscarinic receptors. In each assay run, a standard displacement curve was made, adding various concentrations of atropine to the serum of young healthy volunteers taking no medicines. The level of SAA was expressed as atropine equivalents, picomoles of atropine equivalents per milliliter serum (nM), according to the $\left[{ }^{3} \mathrm{H}\right]$ QNB counts in the patient's serum. 
Table 2. List of medicines prescribed to the patients in the SAA+ and SAA-groups

a Psychotropic medicines

\begin{tabular}{|c|c|c|}
\hline & $\mathrm{SAA}+$ & SAA- \\
\hline $\begin{array}{l}\text { Benzodiazepines } \\
\text { and hypnotics }\end{array}$ & $\begin{array}{l}\text { bromazepam } \\
\text { brotizolam } \\
\text { diazepam } \\
\text { etizolam } \\
\text { triazolam } \\
\text { zopiclone } \\
\text { quazepam (2) } \\
\text { nitrazepam }\end{array}$ & $\begin{array}{l}\text { alprazolam } \\
\text { etizolam } \\
\text { flunitrazepam } \\
\text { oxazolam } \\
\text { triazolam (2) } \\
\text { rilmazafone } \\
\text { zopiclone }\end{array}$ \\
\hline $\begin{array}{l}\text { Antiparkinsonian } \\
\text { agents }\end{array}$ & $\begin{array}{l}\text { biperiden } \\
\text { levodopa }\end{array}$ & $\begin{array}{l}\text { biperiden } \\
\text { levodopa }\end{array}$ \\
\hline Antidementia agents & $\begin{array}{l}\text { donepezil (4) } \\
\text { nicergoline }\end{array}$ & donepezil (4) \\
\hline Antidepressants & $\begin{array}{l}\text { fluvoxamine } \\
\text { paroxetine }(2) \\
\text { trazodone }(2)\end{array}$ & $\begin{array}{l}\text { fluvoxamine } \\
\text { imipramine }\end{array}$ \\
\hline Antiepileptics & $\begin{array}{l}\text { sodium valproate } \\
\text { carbamazepine }\end{array}$ & sodium valproate \\
\hline Antipsychotics & $\begin{array}{l}\text { haloperidol (3) } \\
\text { quetiapine (2) } \\
\text { risperidone (2) } \\
\text { tiapride (2) } \\
\text { olanzapine } \\
\text { perospirone }\end{array}$ & $\begin{array}{l}\text { risperidone (2) } \\
\text { sulpiride (2) } \\
\text { propericiazine } \\
\text { tiapride } \\
\text { vegetamin B }\end{array}$ \\
\hline
\end{tabular}

Numbers of patients prescribed this medicine are provided in parentheses. b Nonpsychotropic medicines

\begin{tabular}{|c|c|}
\hline $\mathrm{SAA}+$ & SAA- \\
\hline $\begin{array}{l}\text { alfacalcidol } \\
\text { ambroxol hydrochloride } \\
\text { amlodipine besylate } \\
\text { benproperine phosphate } \\
\text { bufferin } \\
\text { calcium lactate } \\
\text { candesartan cilexetil (2) } \\
\text { carbocisteine } \\
\text { cinal } \\
\text { digoxin } \\
\text { furosemide } \\
\text { fursultiamine } \\
\text { ibudilast } \\
\text { magnesium oxide } \\
\text { methotrexate } \\
\text { nifedipine ( } 3 \text { ) } \\
\text { nitrendipine } \\
\text { potassium L-aspartate (2) } \\
\text { pravastatin sodium } \\
\text { prednisolone } \\
\text { propiverine hydrochloride } \\
\text { rebamipide } \\
\text { sennoside } \\
\text { seven EP } \\
\text { tamsulosin hydrochloride } \\
\text { ticlopidine hydrochloride } \\
\text { tocopherol acetate } \\
\text { verapamil hydrochloride }\end{array}$ & $\begin{array}{l}\text { alacepril } \\
\text { allopurinol } \\
\text { senna (2) } \\
\text { amlodipine besylate (2) } \\
\text { arotinolol hydrochloride } \\
\text { aspirin } \\
\text { atenolol } \\
\text { bezafibrate } \\
\text { bufferin } \\
\text { cefadroxil } \\
\text { chlorpheniramine maleate } \\
\text { digitoxin } \\
\text { doxazosin mesylate } \\
\text { famotidine (2) } \\
\text { furosemide (2) } \\
\text { glycyron } \\
\text { magnesium oxide } \\
\text { marzulene-S } \\
\text { mecobalamin (2) } \\
\text { naftopidil } \\
\text { nicorandil (2) } \\
\text { nifedipine (2) } \\
\text { nitroglycerin } \\
\text { oxitropium bromide } \\
\text { oxybutynin hydrochloride } \\
\text { senna (2) } \\
\text { sennoside (3) } \\
\text { simvastatin } \\
\text { spironolactone } \\
\text { tamsulosin hydrochloride } \\
\text { temocapril hydrochloride } \\
\text { teprenone } \\
\text { theophylline } \\
\text { tiopronin } \\
\text { tocopherol nicotinate } \\
\text { ubidecarenone } \\
\text { valsartan }\end{array}$ \\
\hline
\end{tabular}

We compared SAA levels between the SAA+ group and the SAA- group. The statistical analysis comparing group means was conducted using Student's t test. Items that were significantly different between the 2 groups became candidate variables for logistic regression analysis. $\mathrm{p}<0.05$ was accepted as a statistically significant value. The data were analyzed by the statistical software package SPSS-12.0J (Statview Inc., Tokyo, Japan).

We obtained informed consent from all study subjects or their proxies before conducting the study. This study was approved by the ethical committee of the National Shimofusa Hospital.

Influence of SAA on Clinical Symptoms of $\mathrm{AD}$

\section{Results}

The relationship between atropine concentration (the amount of atropine in standard solution, given in nanomoles per liter) and $\left[{ }^{3} \mathrm{H}\right] \mathrm{QNB}$ counts (radiolabeled tritiated QNB counts, given in disintegrations per minute, $\mathrm{dpm}$ ) is linear from 1.95 to $25 \mathrm{nM}$. Any SAA level over the detection limit is defined as SAA+. Among the $76 \mathrm{AD}$ patients in this study, 26 patients were SAA+ and 50 patients 
Table 3. Mean total scores for each BEHAVE-AD symptom domain in the SAA+ and SAA-groups

\begin{tabular}{lllr}
\hline & SAA & SAA- & \multicolumn{1}{c}{$\mathrm{p}$} \\
\hline Delusion & $3.4(1.3)^{*}$ & $1.2(1.7)$ & $<0.0001$ \\
Hallucination & $1.9(1.0)^{*}$ & $0.7(1.0)$ & $<0.0001$ \\
Activity disturbance & $2.3(2.2)$ & $2.1(2.2)$ & 0.7162 \\
Aggressiveness & $1.9(2.1)$ & $1.1(1.7)$ & 0.0714 \\
Rhythm disturbance & $1.7(0.7)^{*}$ & $0.6(0.8)$ & $<0.0001$ \\
Affection & $0.6(0.8)$ & $1.0(1.2)$ & 0.1590 \\
Anxiety & $1.7(1.8)$ & $1.4(1.8)$ & 0.6278 \\
\hline
\end{tabular}

Data are given as means with SD in parentheses. Delusion = Paranoid and delusional ideation; rhythm disturbance $=$ diurnal rhythm disturbances; affection = affective disturbances; anxiety $=$ anxieties and phobias. ${ }^{*} \mathrm{p}<0.05$ (Student's $\mathrm{t}$ test).

were SAA-. The mean SAA value \pm SD in the SAA+ group was $4.14 \pm 2.70 \mathrm{nM}$.

Table 1 shows the demographic data, the total score of MMSE, the number of psychotropic medicines taken and the number of nonpsychotropic medicines taken, both in the SAA+ and the SAA- groups. Table 2 shows the lists of medicines prescribed to patients in the SAA+ and the SAA- groups. Nine medicines in the SAA+ group and 3 medicines the SAA- group were not elucidated. The prescribed psychotropics were antipsychotics, antidepressants, antiparkinsonian drugs, benzodiazepines and hypnotics, antidementia agents and antiepileptics. The prescribed nonpsychotropics were mostly cardiovascular medicines $\left(\mathrm{Ca}^{2+}\right.$ antagonists, $\beta$-blockers, angiotensin II antagonists, angiotensin-converting enzyme inhibitors, etc.), antipulmonary disease agents and antiprostatic hyperplastic agents. SAA+ AD patients have a tendency to be prescribed many antidepressants and antipsychotics. Especially the number of patients who took antipsychotics was as high as 9 in the SAA+ group (9/26 patients), compared with 6 in the SAA- group (6/50 patients; $\chi^{2}$ test: $p=0.0315)$. Similarly, the rates of prescribed antidepressants in SAA+ and SAA- patients were $5 / 26$ and $1 / 50$, respectively $\left(\chi^{2}\right.$ test: $\left.p=0.0161\right)$. Moreover, $S A A+$ patients were prescribed more antipsychotics that possess potent anticholinergic activity, such as olanzapine, quetiapine and risperidone. The rates of prescribed antiparkinsonian drugs, benzodiazepines and hypnotics in the SAA+ and SAA- groups were mostly equivalent. The rates of prescribed nonantipsychotic medicines in the SAA+ and SAA- groups were mostly equivalent. The numbers of nonpsychotropic medicines were equally prescribed to patients both in the SAA+ and the SAA- group; however, the highest number of prescribed nonpsychotropic medicines to one patient was 10 , and the patient was in the SAA+ group. AD patients have a tendency to be prescribed many nonpsychotropic medicines.

Table 3 shows the scores of each item on the BEHAVE$\mathrm{AD}$ for the 2 groups. There were no significant differences in sex distribution, educational level, age at onset of dementia and age at the time of test between the SAA+ group and the SAA- group. The total mean MMSE scores, however, were lower in the SAA+ group than in the SAAgroup, while the FAST score, the scores for paranoid and delusional ideation, hallucinations and diurnal rhythm disturbances on the BEHAVE-AD as well as the number of prescribed psychotropic medicines were significantly $(p<0.05)$ higher in the SAA+ group than in the SAAgroup.

We performed a logistic regression analysis using SAA as the dependent variable, and significant univariate values of FAST scores, total MMSE score, total scores for paranoid and delusional ideation, hallucinations and diurnal rhythm disturbances on the BEHAVE-AD and total number of psychotropic medicines as the independent variables, and the logistic regression analysis revealed that there were significant $(\mathrm{p}<0.05)$ correlations between SAA and the total scores for paranoid and delusional ideation, and the diurnal rhythm disturbances of the BEHAVE-AD, respectively.

\section{Discussion}

When we detected SAA in AD patients at first admission to our hospital, 26 out of $76 \mathrm{AD}$ patients (34.2\%) were found to be SAAt. Our detected rate of SAA+ patients was lower than that reported by Mulsant et al. [3] in community dwellings, which was 180 out of 201 subjects (89.6\%). We found about one third of the $\mathrm{AD}$ patients to be SAA+ at first admission to hospital, and the mean value of SAA was $4.14 \pm 2.70 \mathrm{nM}$. Tune et al. [12] reported that SAA at $7.5 \mathrm{nM}$ and higher concentrations in postoperative nondemented patients was associated with a higher risk of delirium. On the other hand, Tune and Coyle [1] commented that SAA at $3.5 \mathrm{nM}$ and higher concentrations was required to show a beneficial effect in schizophrenic patients taking antipsychotics in order to avoid extrapyramidal side effects, striking a balance between dopaminergic and acetylcholinergic neuronal activity. Our detected mean concentration of SAA of $4.14 \pm 2.70$ $\mathrm{nM}$ is lower than that which risks causing delirium in 
postoperative nondemented patients, and somewhat higher than the lower limit to avoid extrapyramidal side effects in schizophrenic patients reported by Tune and Coyle [1]. It is quite probable, however, that even low values of SAA could affect cognition and BPSD in AD patients (although having no effect on cognition in nondemented patients) [6, 7]. Anticholinergic activity easily deteriorates the $\mathrm{AD}$ symptoms.

The number of prescribed psychotropic medicines was significantly $(\mathrm{p}<0.05)$ higher in the SAA+ group. This result confirms previous expectations. Most psychotropic medicines have anticholinergic activity and are known to cause cognitive dysfunctions [2, 13, 14]. However, we commented that even if each medicine has little anticholinergic activity, a positive SAA could be the consequence of cumulatively prescribed medicines [2]. In fact, in the SAA+ group the rates of patients prescribed with antipsychotics or antidepressants were significantly higher than those in SAA- group; however, the numbers of antiparkinsonian drugs, benzodiazepines and hypnotics with potent anticholinergic activity in the SAA+ and SAA- groups were mostly equivalent, and the rates of prescribed antipsychotics and antidepressants were relatively low. We emphasized that the anticholinergic activity in the serum is caused by the cumulatively prescribed medicines, even though each medicine has no, or no prominent, anticholinergic activity [2]. Therefore, the more kinds of psychotropic medicine we prescribe, the more the SAA tends to be positive. Some of our patients who showed BPSD were prescribed psychotropic medicines and thus showed positive SAA even at study entry. Moreover, psychotropic medicines have prominent anticholinergic activity and are known to cause cognitive dysfunctions, especially in AD patients [6, 7]. Accordingly, the more kinds of nonpsychotropic medicine we prescribe, the more SAA tends to be positive because many nonpsychotropic medicines for cardiac disorders, urinary tract disorders, gastrointestinal disorders and other disorders have prominent anticholinergic properties [2]. However, regarding nonpsychotropic medicines, because patients with active physical symptoms or with severe physical illnesses were not referred, there was no significant difference in the number of nonpsychotropic medicines between the SAA+ group and the SAA- group. In fact, one patient who was prescribed with 10 nonpsychotropic medicines, without any psychotropic medicine, showed positive SAA. We considered that the higher the number of nonpsychotropic medicines prescribed was, the more the SAA would tend to be positive, as with psychotropic medicines. However, we avoided any de-

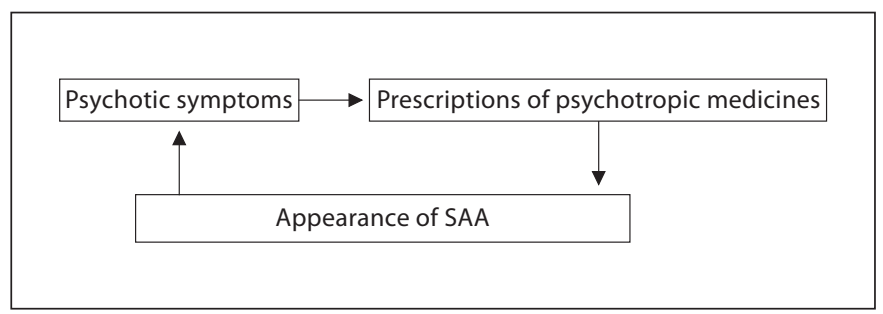

Fig. 1. SAA is induced by prescribed psychotropic medicines, and this anticholinergic activity causes clinical symptoms, especially psychiatric symptoms. Moreover, we prescribe psychotropic medicines to prevent clinical symptoms, mainly psychiatric symptoms of aggressiveness, plus hallucinations and delusions. We considered that these 3 factors (appearance of SAA, psychotic symptoms and prescription of psychotropic medicines) participated in the loop. We refer to this loop relationship as the 'vicious circle of anticholinergic activity in AD'. However, because our report was a cross-sectional one, we could not elucidate the causal relationships among these factors (appearance of SAA, psychotic symptoms and prescription of psychotropic medicines). Therefore, this hypothesis should be experimentally tested.

finitive conclusion because not all prescribed medicines were elucidated. Of course, the prescribed medicines were not the only cause of anticholinergic burden. For example, Flacker and Lipsitz [15] commented that SAA might reflect a nonspecific stress response to illness in elderly people. In fact, 9 patients in the SAA+ group were prescribed with no medicine. However, prescribed medicines, especially psychotropic medicines, were one of the main causes of positive SAA in AD patients.

Although there were no significant differences in sexual distribution, educational level, age at onset of dementia and age at the time of test between the SAA+ group and the SAA- group, the total MMSE score was significantly $(\mathrm{p}<0.05)$ lower in SAA+ group than in the SAAgroup, while the FAST score and BEHAVE-AD score involving the items of paranoid and delusional ideation, hallucinations and diurnal rhythm disturbances were significantly $(\mathrm{p}<0.05)$ higher in SAA+ group. Moreover, logistic regression analysis revealed that there were significant $(\mathrm{p}<0.05)$ correlations between SAA and the total scores for paranoid and delusional ideation, and the diurnal rhythm disturbances of the BEHAVE-AD, respectively. These results indicate that SAA in AD patients is associated with cognitive dysfunction, disturbances of the diurnal rhythm as well as paranoid delusion and hallucination. Tune et al. [12], Flacker and Lipsitz [15] and Mach Jr. et al. [16] reported that elevated SAA in elderly patients is associated with higher rates of delirium. It is 
conceivable that cognitive reduction, delusions, hallucinations and diurnal rhythm disturbances (similar to symptoms of delirium) were consequences of anticholinergic activity. Cummings [17] and Lemstra et al. [18] commented that central cholinergic deficiency was clinically characterized by neuropsychiatric symptoms rather than by cognitive impairments. Our findings are that delusions and diurnal rhythm disturbance are more strongly affected by SAA than cognitive function, and they support the comments by Cummings [17] and Lemstra et al. [18]. Similar results were also found by Mulsant et al. [19], who reported that a higher value of anticholinergic activity was associated with higher scores on the Neuropsychiatric Inventory, especially for delusion.

From our results, the clinical symptoms (cognitive dysfunction and BPSD) and the prescription of psychotropic medicines were factors related to SAA, especially hallucination and disturbed diurnal rhythm. Because our report was a cross-sectional study, we could not elucidate the causal relationships among these factors (the clinical symptoms, the prescription of psychotropic medicines and SAA). However, we speculated that there might be cyclic relationships among these three factors - we termed this the 'vicious cycle of anticholinergic activity in $\mathrm{AD}^{\prime}$ (fig. 1) - and that there might be an endogenous anticholinergic factor. Medicines with potent anticholinergic activity or the prescription of many kinds of medicine cause positive SAA, and anticholinergic activity worsens clinical psychiatric symptoms. However, in general we prescribe psychotropic medicines for the clinical psychiatric symptoms of agitation and psychosis in $\mathrm{AD}$ $[20,21]$. Therefore, the relationship among prescribed psychotropic medicines, SAA and clinical symptoms, es- pecially hallucination and disturbed diurnal rhythm, might be a cyclic one.

Secondly, there is a high probability that the pathogenesis of $\mathrm{AD}$ concerns neuronal degeneration by oxidative stress [22], and it has been shown that amyloid- $\beta$ peptide might have the ability to generate free radicals. On the other hand, an endogenous ligand of the muscarinic receptor in the AD brain has been detected, more than in the nondemented control brain, and the endogenous ligand of the muscarinic receptor seems to be a low-molecular substance of 100-1,000 Da which has been catalyzed by oxidation [23]. It is possible that SAA does not always derive from prescribed psychotropic medicines, but also from endogenous oxidative products [15].

Therefore, psychiatrists should first treat with medicines which activate cholinergic neuronal activity and reduce oxidative stress, then treat with psychotropic medicines with weak or no anticholinergic activity. Of course, because our report was a cross-sectional one, no causal relationships could be established, and this hypothesis should be experimentally tested. It is, however, important to realize that - whether there are cyclic relationships among these three factors or not, and whether SAA is exogenous or endogenous - SAA plays a role in the psychiatric symptoms of $\mathrm{AD}$.

The limitations of this study included a small sample size, absence of control subjects, and that this study was a cross-sectional one, with no longitudinal course of SAA. Further investigations using longitudinal observations of large samples would be necessary to delineate a more precise relationship between SAA and clinical symptoms (especially BPSD) in AD.

\section{References}

1 Tune L, Coyle JT: Serum levels of anticholinergic drugs in treatment of acute extrapyramidal side effects. Arch Gen Psychiatry 1980;37:293-297.

-2 Tune L, Carr S, Hoag E, Cooper T: Anticholinergic effects of drugs commonly prescribed for the elderly: potential means for assessing risk of delirium. Am J Psychiatry 1992;149:1393-1394.

-3 Mulsant BH, Pollock BG, Kirshner M, Shen C, Dogde H, Ganguli M: Serum anticholinergic activity in a community-based sample of older adults: relationship with cognitive performance. Arch Gen Psychiatry 2003;60: 198-203.
4 Chan WY, Setter SM, Sclar DA, Salek S, Corbett C, Henliksen AL: The use of anticholinergic medications in homebound elderly patients with dementia. Consult Pharm 2006; 21:391-399.

5 Huey ED, Taylor JL, Luu P, Oehlert J, Tinklenberg JR: Factors associated with use of medications with potential to impair cognition or cholinesterase inhibitors among Alzheimer's disease patients. Alzheimers Dement 2006;2:314-321.

6 Sunderland T, Tariot PN, Cohen RM, Weingartner H, Mueller EA 3rd, Murphy DL: Anticholinergic sensitivity in patients with dementia of Alzheimer type and age-matched control: a dose-response study. Arch Gen Psychiatry 1987;44:418-426.
7 Thienhaus OJ, Allen A, Bennett JA, Chopra YM, Zemlan FP: Anticholinergic serum levels and cognitive performance. Eur Arch Psychiatry Clin Neurosci 1990;240:28-33.

-8 McKhann G, Drachman D, Folstein M, Katzman R, Price D, Stadlan EM: Clinical diagnosis of Alzheimer's disease: report of the NINCDS-ADRDA Work Group under the auspices of Department of Health and $\mathrm{Hu}$ man Services Task Force in Alzheimer's Disease. Neurology 1984;34:939-944.

-9 Reisberg B: Functional assessment staging (FAST). Psychopharmacol Bull 1988;24: 653-659.

Hori/Konishi/Watanabe/Uchida/Tsuboi/ Moriyasu/Tominaga/Hachisu 
$D_{10}$ Folstein MF, Folstein SE, McHugh PR: 'Mini-Mental State': a practical method for grading the cognitive state of patients for the clinician. J Psychiatr Res 1975;12:189-198.

-11 Reisberg B, Borenstein J, Salob SP, Ferris SH, Franssen E, Georgotas A: Behavioral symptoms in Alzheimer's disease: phenomenology and treatment. J Clin Psychiatry 1987; 48(suppl):9-15.

-12 Tune LE, Damlouji NF, Holland A, Gardner TJ, Folstein MF, Coyle JT: Association of postoperative delirium with raised serum levels of anticholinergic drugs. Lancet 1981;2:651-653.

-13 Salzman C, Fisher J, Nobel K, Glassman R, Wolfson A, Kelley M: Cognitive improvement following benzodiazepine discontinuation in elderly nursing home residents. Int J Geriatr Psychiatry 1992;7:89-93.
14 Tönne U, Hiltunen AJ, Vikander B, Engelbrektsson K, Bergman H, Bergman I, Leifman H, Borg S: Neuropsychological changes during steady-state drug use, withdrawal and abstinence in primary benzodiazepinedependent patients. Acta Psychiatr Scand 1995;91:299-304.

15 Flacker JM, Lipsitz LA: Serum anticholinergic activity changes with acute illness in elderly medical patients. J Gerontol A Biol Sci Med Sci 1999;54:M12-M16.

16 Mach JR Jr, Dysken MW, Kuskowski M, Richelson E, Holden L, Jilk M: Serum anticholinergic activity in hospitalized older persons with delirium: a preliminary study. J Am Geriatr Soc 1995;43:491-495.

17 Cummings JL: Cholinesterase inhibitors: a new class of psychotropic compounds. Am J Psychiatry 2000;157:4-15.

18 Lemstra AW, Eikelenboom P, van Gool WA: The cholinergic deficiency syndrome and its therapeutic implications. Gerontology 2003 49:55-60.

-19 Mulsant BH, Gharabawi GM, Bossie CA, Mao L, Martinez RA, Tune LE, Greenspan AJ, Bastean JN, Pollock BG: Correlates of anticholinergic activity in patients with dementia and psychosis treated with risperidone or olanzapine. J Clin Psychiatry 2004;65:1708-1714.
20 Chien IC, Hsu JH, Bih SH, Lin CH, Chou YJ, Lee $\mathrm{CH}$, Chou P: Prevalence, correlates, and disease patterns of antipsychotic use in Taiwan. Psychiatry Clin Neurosci 2008;62:677684.

21 Wood-Mitchell A, James IA, Waterworth A, Swann A, Ballard C: Factors influencing the prescribing of medications by old-age psychiatrists for behavioural and psychological symptoms of dementia: a qualitative study. Age Ageing 2008;37:547-552.

22 McGeer PL, McGeer PG: The inflammatory response system of brain: implications for therapy of Alzheimer and other neurodegenerative disease. Brain Res Brain Res Rev 1995;21:195-218.

23 Frey WH 2nd, Emory CR, Wiebenga ME, Saxena S, Cardelli D, Ala TA, Tollefson GD: Inhibitor of antagonist binding to muscarinic receptor is elevated in Alzheimer's brain. Brain Res 1994;655:153-160. 